\title{
圆 \\ The Interaction Effect of Heuristic Representation on Initial Public Offering Anomaly: Evidence from Flipping Activity
}

\author{
Hon-Wei Leow ${ }^{1}$ and Wee-Yeap Lau ${ }^{2}$
}

\begin{abstract}
This study examines the impact of the heuristic representation on IPO anomaly in the context of an emerging market from January 2006 to December 2016. Models consist of multiple regression has been evaluated. Our results show: firstly, the distribution of initial return, oversubscription ratio, firm age, offer period, firm size, heuristic representation, and flipping activity are positively skewed; Secondly, the oversubscription ratio has a positive relationship with flipping activity. This is because higher demand makes investors flip more to liquidate the IPO on the first trading day. In contrast, firm size has a negative relationship with flipping activity. A larger IPO firm is more stable in terms of performance, and less risky in terms of business operation; Thirdly, heuristic representation influences the relationship between oversubscription ratio and flipping activity; Lastly, this study dispels the notion that investors are active in subsequent trading but not necessarily obtain a profit from the liquidation. This study extends earlier work by examining the interaction effect of heuristic representation to the flipping activity in an emerging market.
\end{abstract}

JEL classification: E22, G01, G11, G24

Keywords: Heuristic representation, IPO anomaly, Initial return, Oversubscription ratio, Firm size, Flipping activity.

\footnotetext{
${ }^{1}$ University of Malaya, Malaysia honwei2017@hotmail.com

${ }^{2}$ University of Malaya, Malaysiawylau@um.edu.my
} 


\section{Introduction}

The IPO research in aftermarket trading has obtained considerable attention in recent years, especially in the U.S. These studies mainly focused on the aspect of price stabilization by IPO underwriter. The process of price stabilization is called flipping activity where the disposal of share by the IPO subscriber on the first trading day. In Australia, this is known as "stagging" activity, but this issue only has limited attention in Malaysia.

According to Hanley et al. (1993), Aggarwal (2000), Ellis et al. (2000), Aggarwal et al. (2002) and Fishe (2002), IPO underwriter plays an essential role in the flipping activity. They serve as the market maker who stabilize the downward pressure of share price from flipping activity by the IPO subscriber. Therefore, the net buying from the underwriter in the aftermarket trading could stabilize the IPO price, especially during the weak IPO offering (Carter and Dark, 1993).

In the weak IPO offering, the flipping cost is expensive for underwriters, and this is known as IPO inventory risk. When the inventory risk becomes higher, investors will have less interest to buy the share in the secondary market, and hence lesser IPO subscription. According to Correra (1992), underwriters always at "war against IPO flippers" to reduce IPO inventory risk. They deter flipping activity from those flippers who dispose of the shares in a short period.

Besides, Hanley et al. (1996) highlight that flipping activity creates problem to the IPO syndicate. For instance, co-managers involve in IPO distribution and aftermarket trading. They acquire $8.7 \%$ of the shares offered on the first trading day. Meanwhile, the underwriter is $58.8 \%$ (Ellis et al., 2000). This helps co-managers to allocate the shares more effectively and leads to price stabilization, especially during weak IPO offering. For flippers, they reduce the searching cost and encourages more long-term investors (Hanley et al., 1996).

In this paper, there are two considerations in flipping activity: First, the underwriter discourages an investor from selling share from the subscription on the first trading day. If there is a higher liquidation, the flipping activity will cause the poor IPO performance; Second, if the flipping activity is inactive, there will be no aftermarket trading, and the demand of subsequent trading will be reduced, causing lesser price movement.

The motivation of this study is from two critical arguments. First, the flipping activity in Malaysian IPO is different as compared to the U.S. market. For instance, the U.S. underwriters involve more frequently in price stabilization in aftermarket trading. In contrast, flipping activity in Malaysia is common, but this is supported by the high initial return and demand in the secondary market. According to Wong (2005), though IPO price support is illegal, the underwriter and IPO syndicate still involve in aftermarket trading.

Second, the Malaysian IPO is unique in terms of allocation, which is a private placement offering. For instance, the underwriter identifies a group of institutional investors such as banks, mutual funds, insurance companies, pension funds, and gives the priority for them to subscribe to newly issued share. This is known as a non-public offering which helps to support the downward pressure of share price. 
Leow \& Lau | The Interaction Effect of Heuristic Representation on Initial Public Offering Anomaly

According to Shiller (2003), the representative heuristic is defined as a "tendency for people to categorize events as typical or representative of a well-known class". The representative heuristic asserts that individuals assess the likelihood of an event to occur by similar outcomes of its stereotypes (Kahneman and Tversky, 1982). Hence, it is convenient for investors to reply to this type of heuristic for judgment and prediction.

This study will examine whether heuristic representation serves as an interaction role in affecting the relationship between the dependent and independent variables. In our study, flipping activity as measured by trading volume is used to determine the impact of an initial return, oversubscription ratio, firm age, offer period, firm size and heuristic representation. This study contributes to the extant literature on IPO flipping activity with heuristic representation in the context of IPO in an emerging market.

The remainder of the paper is organized as follows. Section two reviews the past literature, followed by data and methodology. Section four discusses the results. The last session concludes the study.

\section{Literature Review}

Numerous research in aftermarket trading (a proxy for flipping) have been conducted to explain the flipping behaviour together with IPO initial return. In the early studies by Miller and Reilly (1987), Schultz and Zaman (1994), they show a positive relationship between initial return and flipping activity. The results are consistent with Ellis et al. (2000) and Aggarwal (2003) who confirm the positive relationship between initial return and flipping activity.

Boehmer and Fishe (2000) argue that IPOs are costly to obtain greater liquidity in aftermarket trading. They explain that the underwriter sets a lower offer price intentionally to receive better demand and initial return. This induces the flipping from low valuation investors to high valuation investors that lead to high post-listing liquidity and initial return of the IPO. In most of the IPO markets, the underwriter does not have the authority to interfere in aftermarket trading. However, with a significant initial return, it affects the selling decision of investors and leads to lower flipping activity.

There are many studies done in the U.S. market on IPO flipping activity (Krigman et al., 1999; Bash, 2001; Aggarwal, 2003; Gounopoulos, 2006). Krigman et al. (1999) and Bash (2001) study the relationship between pricing error and flipping activity of the long-term IPO performance. Their results show that flipping activity is not the main factor that causes poor aftermarket performance. However, flipping is negatively explained by initial return and market capitalization.

The flipping activity is not limited to retail investors but also available for institutional investors. According to Benveniste and Spindt (1989), there is a negative relationship between initial return and institutional flipping. The result is similar to Krigman et al. (1999) and Bash (2001), both findings show that flipping activity is more significant during the negative initial return, especially during the weak IPO offering. 
Besides, Aggarwal (2003) uses 617 IPOs sample from May to June 1998; the results show that institutional investors flip more than retail investors in hot IPO. In contrast, Gounopoulos (2006) shows that institutional investors flip more than retail investors in cold IPO and when a larger size is issued. These findings conclude that institutional investors are also aggressive in IPO flipping activity, indicating a response to the IPO performance.

In Malaysia context, studies from Chong et al. (2009) and Chong (2009) find the flipping activity in the aspect of behaviour finance from 1991 to 2003 with a total sample of 132 IPOs. Their results show that the noise effect and disposition effect has a positive relationship with flipping activity, and there is a negative relationship between issue size and flipping activity. Their results are consistent with Islam \& Munira (2004).

The studies from Sapian et al. (2012) and Abdul-Rahim et al. (2013) find the flipping activity is significantly related to initial return, institutional investors, and offer size. Their results conclude that higher initial return and higher institutional participation bring higher flipping activity; Meanwhile, larger issue size brings lower flipping activity.

Besides, Chong et al. (2011) show that there is a negative relationship between heuristic representation and flipping activity. The result is consistent with Shefrin and Statman (1993) and Shiller (2003). They show that heuristic representation influences the decision making from an investor from the perspective of behavioral finance.

In the stock market, heuristic representation is a judgment bias that can help an investor to estimate a stock is either winner or loser, and the market is either bull or bear which according to past events. The study from Tversky and Kahneman (1983) shows the intuitive prediction based on the similarity of the evidence and possible outcome that cause the judgement bias for an investment.

Shefrin and Statman (1993) also indicate the heuristic representation lead an investor to be more optimistic due to experiences on the past gains and pessimistic due to experiences on the past losses. Heuristic representation helps to make a quick decision, but it can be risky for investment because not all information is carefully considered, and resulted with the fallacy. Bayley et al. (2006) show a positive relationship between heuristic representation and the investor's decision to flip from both Australian institutional investor and individual investor.

Besides, according to Che-Yahya et al. (2014), they study the sentiment of shareholders through the impact of the lock-up period to the flipping activity. This study focuses on the different length of time affects the different sentiments of the major shareholders to hold on to the IPO. They found a negative relationship between lock-up period and flipping activity. This is because a more extended lock-up period causes significant shareholders to hold the shares for good IPO.

Our study is different from Che-Yahya et al. (2014). First, judgment bias exists when an investor or shareholder is allowed to liquidate the IPO on the first trading day. Second, the sentiment of the investor or shareholder may change because they are more concerned about the share performance rather than business performance. 
Leow \& Lau | The Interaction Effect of Heuristic Representation on Initial Public Offering Anomaly

Besides, Leow and Lau (2018a) study the investor's sentiment on the first day of trading during the Global Financial Crisis. The results show that investors still able to gain about 1 to 3 per cent of returns during the crisis period among the new issues on the first day of trading, even the investor's sentiment is low. The market sentiment for IPO was at its worst period during the Global Financial Crisis, and the investors did not want to hold on to the IPO. According to Leow and Lau (2018b), a more detailed study on the high-low intraday performance of IPO during the Global Financial Crisis. The result indicates a total return of -5 to 11 per cent during the crisis period. It can be concluded that there is still a positive return as an investor's sentiment is low during the crisis period.

Therefore, this study examines the relationship between variables such as initial return, oversubscription ratio, firm age, offer period, firm size and heuristic representation. Moreover, this study is different from previous literature by focusing on the interaction effect of heuristic representation which is the judgment bias when an investor is allowed to liquidate the IPO on the first trading day.

\section{Data and Methodology}

This paper uses 186 IPOs which are listed on Bursa Malaysia from January 1, 2006, to December 31, 2016. The IPO information such as offer price, closing price, offer period and unit offer can be obtained from Bursa Malaysia website; Firm age can be obtained from the annual report; Oversubscription ratio and trading volume can be found from the newspaper on the next day of IPO debut.

In order to have a comprehensive understanding of the impact of heuristic representation on the flipping activity, this paper examines the interaction effect of the heuristic representation on the relationship between an independent variable and dependent variable. The conceptual framework and relevant hypotheses are shown in Figure 1.

In equation (1), the dependent variable is IPO flipping activity as measured by the liquidity, $F A_{i}=$ (volume/unit offer) x100. Besides, the independent variables consist of IPO initial return, oversubscription ratio, firm age, offer period firm size and heuristic representation. In equation (2), the interaction effect of heuristic representation is measured by the equally weighted initial return of IPO, $\left.\left.I_{i}=\sum\left[\left(\mathrm{P}_{t}-\mathrm{P}_{\mathrm{t}-1}\right) / \mathrm{P}_{\mathrm{t}-1}\right)+\ldots \ldots . .\left(\mathrm{P}_{\mathrm{t}}-\mathrm{P}_{\mathrm{t}-\mathrm{n}}\right) / \mathrm{P}_{\mathrm{t}-\mathrm{n}}\right)\right] \times(100)$. It is calculated as the average on the percentage change in price from offer price to the closing price on the first day of trading.

$$
\begin{aligned}
& F A_{i}=\alpha_{0}+\alpha_{1} I R_{i}+\alpha_{2} O S R_{i}+\alpha_{3} \log A G E_{i}+\alpha_{4} \log O P_{i}+\alpha_{5} \operatorname{LogSize}+\alpha_{6} H R_{i}+\varepsilon_{i} \\
& F A_{i}=\beta_{0}+\beta_{1} I R_{i}+\beta_{2} O S R_{i}+\beta_{3} \log A g e_{i}+\beta_{4} \log O P_{i}+\beta_{5} \operatorname{LogSize}_{i}+\beta_{6} H R_{i}+\beta_{7} I R_{i} * H R_{i} \\
& +\beta_{8} \mathrm{OSR}_{i} * H R_{i}+\beta_{9} \log \mathrm{Age}_{i} * H R_{i}+\beta_{10} \operatorname{LogOP} * H R_{i}+\beta_{11} \operatorname{LogSize}_{i} * H R_{i}+\varepsilon_{i}
\end{aligned}
$$

\section{Where:}

$F A_{i}$ is flipping activity that denotes the percentage of trading volume divided by the number of shares issued on the first day of trading of the $i$ th company. (Aggarwal, 2003) 
$\mathrm{IR}_{i}$ is the initial return that denotes the percentage change in price from the offer price to the closing price on the first day of trading of the $i$ th company. (Dawson, 1987)

$O S R_{i}$ is oversubscription ratio that denotes the number of times an IPO issue is either overdemanded or under-demanded by the group of investors of the $i$ th company. (Yong, 1996)

$\log A G E_{i}$ is the firm age that denotes the number of years since establishment to its listing of the $i$ th company. A $\log$ transformation is applied because of its positive skewness. (Carter and Manaster, 1990; Ritter, 1984)

$\log O P_{i}$ is offer period that denotes the duration of the subscription of the $i$ th company. A $\log$ transformation is applied because of its positive skewness. (Guo and Brooks, 2009)

$\operatorname{LogSize}_{i}$ is the firm size that denotes the number of the unit offers multiply by the offer price of the $i$ th company. A log transformation is applied because of its positive skewness. (Wasserman, 2003)

$H R_{i}$ is heuristic representation denotes the equally weighted initial return for the three most recent new issues listed before the IPO listing. (Tversky and Kahneman, 1974; Shiller, 2003; Bayley et al., 2006)

Figure 1: Conceptual Framework

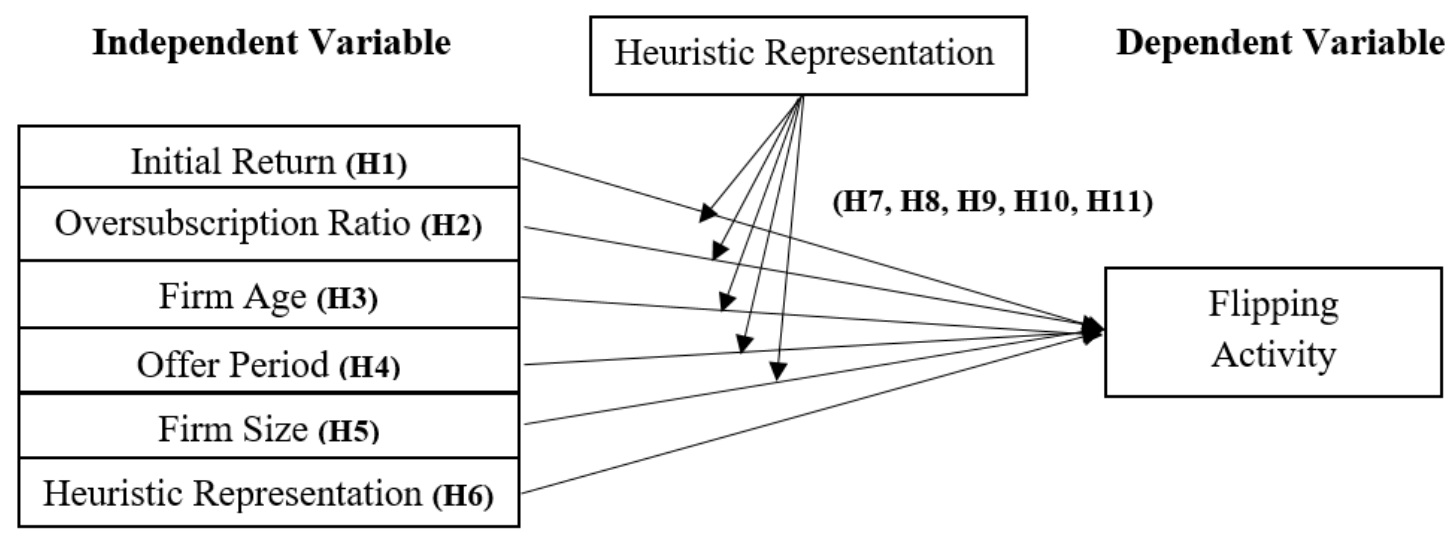

Source: Authors' sketch

Figure 1 shows the conceptual framework of the hypotheses developed based on the expected relationship between the independent variable and dependent variable. This study uses the theory of finance from IPO initial return and examines the following hypotheses:

H1: There is a positive relationship between initial return and flipping activity.

H2: There is a positive relationship between the oversubscription ratio and flipping activity.

H3: There is a negative relationship between firm age and flipping activity.

H4: There is a positive relationship between the offer period and flipping activity.

H5: There is a negative relationship between firm size and flipping activity.

H6: There is a positive relationship between heuristic representation and flipping activity. 
Leow \& Lau | The Interaction Effect of Heuristic Representation on Initial Public Offering Anomaly

H7: There is an interaction effect of the initial return and heuristic representation to the flipping activity.

H8: There is an interaction effect of the oversubscription ratio and heuristic representation to the flipping activity.

H9: There is an interaction effect of the firm age and heuristic representation to the flipping activity.

H10: There is an interaction effect of the offer period and heuristic representation to the flipping activity.

H11: There is an interaction effect of the firm size and heuristic representation to the flipping activity.

From the hypotheses, $\mathrm{H} 1$ to $\mathrm{H} 6$ are used to test in equation (1), we expect that initial return, oversubscription ratio, offer period and heuristic representation should have the positive relationship with flipping activity and firm age and firm size have the negative relationship with flipping activity.

$\mathrm{H} 7$ to $\mathrm{H} 11$ is used to test in equation (2) to examine to what extent heuristic representation influences the relationship between initial return, oversubscription ratio, firm age, offer period, firm size and flipping activity. The judgement of investor is varied when subscribing to the IPO, and this causes the demand will be increased or decreased. It is believed that the interaction with the heuristic representation will have an impact on the flipping activity on the first day of trading.

\section{Results}

Table 1: Descriptive statistics for the independent and dependent variables

\begin{tabular}{|c|c|c|c|c|c|c|c|}
\hline & $\mathrm{n}$ & Mean & Median & Std. Dev & Min. & Max. & Jarque-Bera \\
\hline \multicolumn{8}{|l|}{ Variables } \\
\hline Flipping Activity & 186 & 19.21 & 12.59 & 22.43 & 0.00 & 170.70 & $1099.63 * * *$ \\
\hline Initial Return & 186 & 16.35 & 6.52 & 49.08 & -57.30 & 369.50 & $4834.43 * * *$ \\
\hline Oversubscription Ratio & 186 & 19.27 & 9.91 & 31.77 & -12.97 & 315.17 & $13731.21 * * *$ \\
\hline Age & 186 & 14.94 & 11.50 & 14.37 & 0.50 & 90.00 & $16.39 * * *$ \\
\hline Offer Period & 186 & 10.63 & 9.00 & 3.78 & 5.00 & 26.00 & $29.16 * * *$ \\
\hline Size (million) & 186 & 1342.46 & 151.56 & 4699.21 & 19.56 & 40400.00 & $53.97 * * *$ \\
\hline Heuristic Representation & 186 & 16.41 & 9.92 & 29.17 & -22.46 & 124.85 & $232.40 * * *$ \\
\hline
\end{tabular}

Table 1 shows the mean and median of all variables of the 186 IPOs for the entire period from 2006 to 2016. As observed, all variables except age are skewed to the right, as the mean is higher than the median. This is because some of the IPOs offer higher return when there is greater demand than supply. Both initial return and oversubscription ratio are volatile with a higher standard deviation of 49.08 and 31.77, respectively. This is because some IPOs have negative initial return and oversubscription ratio. 
Table 2: Correlation between the explanatory variables

\begin{tabular}{ccrrrrr}
\hline Variables & IR & OSR & Age & OP & Size & HR \\
\hline IR & 1.00 & & & & & \\
OSR & 0.22 & 1.00 & & & & \\
Age & 0.07 & 0.29 & 1.00 & & & \\
OP & 0.10 & -0.06 & 0.10 & 1.00 & & \\
Size & -0.06 & -0.08 & 0.09 & -0.05 & 1.00 & \\
HR & 0.61 & 0.33 & 0.05 & -0.02 & 0.01 & 1.00 \\
\hline
\end{tabular}

Table 3: Regression. Dependent variable: Flipping Activity

\begin{tabular}{lcc}
\hline Independent Variable & coefficient & t statistics \\
\hline Constant & 116.79 & $5.19^{* * *}$ \\
IR & 0.01 & 0.35 \\
OSR & 0.16 & $3.15^{* * *}$ \\
LogAGE & 4.00 & 1.36 \\
LogOP & -10.89 & -0.95 \\
LogSize & -11.05 & $-4.78^{* * *}$ \\
HR & -0.06 & -0.84 \\
\hline Diagnostic test & & \\
\hline Durbin-Watson & 1.89 & \\
VIF & $1.03-1.80$ & \\
R-square & 0.21 & \\
F-value & 7.83 & \\
P-value & 0.00 & \\
\hline Note: *** and ** denote $10 \%, 5 \%$ and $1 \%$ level of significance respectively.
\end{tabular}

Table 2 presents the correlations analysis between the explanatory variables. Notably, the variables such as IPO flipping activity, initial return, oversubscription ratio, firm age, offer period, firm size and heuristic representation used in the analysis are not highly correlated. Therefore, there is no multicollinearity in the model.

As observed in Table 3, the VIF is less than five, and Durbin Watson statistic is near to 2. The oversubscription ratio has a positive and significant relationship with flipping activity. When the demand increases by one time and the IPO flipping activity will increase by 0.16 per cent. This is because higher demand makes investors flip more to liquidate the IPO on the first trading day. The result is consistent with Sapian et al. (2012) and Abdul-Rahim et al. (2013).

Besides, the coefficient for firm size is -10.72 at 1 per cent level of significance. The result shows that firm size has a negative relationship with flipping activity. When the firm size increases by one time and the IPO flipping activity will decrease by 10.72 per cent. This is because the larger scale of the IPO firm, it is more stable in terms of performance, and the risk from the business operation is lower. This attracts substantial investors to hold the larger scale IPO rather than dispose of it, hence lower flipping activity. The result is consistent with Chong et al. (2009), Chong (2009) and Islam and Munira (2004). Overall, on average, the flipping activity is 98.96 per cent. Therefore, $\mathrm{H} 2$ and $\mathrm{H} 5$ are supported. 
Leow \& Lau | The Interaction Effect of Heuristic Representation on Initial Public Offering Anomaly

In Table 3, the variables of initial return, firm age and offer period are not significant statistically. Initial return or quick return is not the aim of rational investors as shown by Islam and Munira (2004), In addition, rational investors are more concern with firm performance as opposed to firm age as concurred by Che-Yahya et al. (2004). Longer offer period enables the investors to study the firm before deciding to subscribe the IPO. As the result, investors who are able to subscribe to good IPO tend to hold it for long-term capital gain. Hence, H1, H3 and H4 are not supported.

Table 4: Results of the interaction effect of heuristic representation to the flipping activity

\begin{tabular}{lcc}
\hline Independent Variable & coefficient & t-statistics \\
\hline Constant & 98.01 & $3.80^{* * *}$ \\
IR & 0.08 & 1.00 \\
OSR & 0.34 & $3.81^{* * *}$ \\
LogAGE & 3.25 & 0.91 \\
LogOP & -2.37 & -0.18 \\
LogSize & -10.07 & $-3.85^{* * *}$ \\
$H R$ & 0.09 & 0.12 \\
$I R^{*} H R$ & -0.0005 & -0.59 \\
OSR $H R$ & -0.0029 & $-2.49^{* * *}$ \\
LogAGE*HR & 0.05 & 0.46 \\
LogOP*H.R. & -0.52 & -1.15 \\
LogSize* HR & 0.04 & 0.52 \\
\hline Diagnostic test & & \\
\hline Durbin-Watson & 1.91 & \\
R-square & 0.20 & \\
F-value & 5.30 & \\
P-value & 0.00 & \\
Note: *** and *** denote $10 \%, 5 \%$ and $1 \%$ level of significance respectively.
\end{tabular}

Table 4 shows the results of the interaction effect of heuristic representation. Oversubscription ratio plays an important role to explain the flipping activity of the IPO. The higher oversubscription ratio reflects higher investor demand for an IPO, a higher flipping activity that leads to higher liquidation on the first trading day. Besides, the larger scale of firm size reflects the capital for an IPO. Hence, a vast paid-up capital will lead to investors to hold on an IPO, and not keen to liquidate on the first trading day.

The result shows that the oversubscription ratio and the firm size are the main factors to explain the flipping activity. However, with the interaction effect of the heuristic representation with oversubscription ratio, when the demand increases by one time and the IPO flipping activity will decrease by 2.49 per cent. This contradicts the results in Table 3, because when the sentiment of the investor has changed (heuristic representation), the IPO demand causes lower flipping activity. It also means that investor is more pessimistic about trading when the sentiment of the investor is weak and causes the investor has changed their trading behaviour (flipping activity). 
In the Malaysian financial market, the demand is essential to encourage investors or speculators to subscribe to an IPO, especially on the first trading day. This resulted in the high trading activity of the IPO. Potential buyers and sellers will trade actively and create higher liquidity to the secondary market. However, the change of investor's sentiment plays an essential role to affect the IPO demand, and the flipping activity will be affected. Therefore, H8 is supported, but H7, H9, H10 and $\mathrm{H} 11$ are not supported.

Table 5 shows a summary of hypotheses tested. Only IPO oversubscription ratio and firm size influence the flipping activity. However, there is an interaction effect of heuristic representation to the relationship between the oversubscription ratio and flipping activity.

Table 5: Hypotheses and Summary of Results

\begin{tabular}{cccc}
\hline Hypotheses & Factors & Predicted Sign & $\begin{array}{c}\text { Hypotheses } \\
\text { Supported }\end{array}$ \\
\hline H1 & IR & + & - \\
H2 & OSR & + & Supported \\
H3 & Age & - & - \\
H4 & OP & + & - \\
H5 & Size & - & Supported \\
H6 & HR & + & - \\
H7 & IR x HR & - & - \\
H8 & OSR x HR & - & Supported \\
H9 & Age x HR & + & - \\
H10 & OP x HR & - & - \\
H11 & Size x HR & -
\end{tabular}

Notes: The dependent variable is flipping activity. The factors consist of initial return (IR), oversubscription ratio (OSR), firm age (Age), offer period (OP), firm size (Size) and heuristic representation (HR). +ve indicates an expectation on the positive relationship while -ve indicates an expectation on the negative relationship. Hypotheses supported by each variable is based on the value reported in table 3 and table 4 .

\section{Conclusion}

In IPO issuance, it is believed that underwriter can gauge the sentiment of different investors, and hence is more proficient in understanding demand and price setting of subsequent trading activities. The success of an IPO depends on the condition of the financial market. However, based on the results of this study, it is found that OSR is positive, firm size is negative, and the initial return is not the primary concern in trading. Hence, it can be concluded that investors are keen to participate in the new IPO issue regardless of the sentiment of investors. This result concurs with Leow and Lau (2018a) as the sentiment of investor does not influence the OSR during the crisis period.

Notably, this study finds: First, the distribution of initial return, oversubscription ratio, firm age, offer period, firm size, heuristic representation, and flipping activity are positively skewed; Secondly, oversubscription ratio has a positive relationship with flipping activity. This is because higher demand makes investors flip more to liquidate the IPO on the first trading day. In contrast, 
Leow \& Lau | The Interaction Effect of Heuristic Representation on Initial Public Offering Anomaly

firm size has a negative relationship with flipping activity. Larger IPO firm tends to show better performance, and the risk from business operation tend to be lower. Thirdly, heuristic representation influences the relationship between oversubscription ratio and flipping activity.

Lastly, this study dispels the notion that investors are active in subsequent trading but not necessarily obtain profit from the liquidation. Besides, the empirical results are robust as both results from the multiple regression and interaction effect yield a similar conclusion.

\section{References}

Abdul-Rahim, R., Sapian, R. Z. Z., Yong, O. and Auzairy, N. A. 2013. Flipping activity and subsequent aftermarket trading in Malaysian IPOs. Asian Academy of Management Journal of Accounting and Finance, 9(1), 113-128.

Aggarwal, R., 2000. Stabilization activities by underwriters after new offerings. The Journal of Finance, 55(3), 1075-1104. https://doi.org/10.1111/0022-1082.00241

Aggarwal, R., Prabhala, N.R. and Puri, M. 2002. Institutional allocations in initial public offerings: Empirical evidence. The Journal of Finance, 57(3), 1421-1442. https://doi.org/10.1111/1540-6261.00465

Aggarwal, R. 2003. Allocation of initial public offerings and flipping activity. Journal of Financial Economics, 68(1), 111-135. https://doi.org/10.1016/S0304-405X(02)00250-7

Bash, A. B. 2001. Post-IPO flipping and turnover: Predictive factors for long-run returns. Available at SSRN: https://ssrn.com/abstract=620164, accessed on 30 September 2019. https://doi.org/10.2139/ssrn.620164

Bayley, L., Lee, P.J. and Walter, T.S. 2006. IPO flipping in Australia: Cross-sectional explanations. Pacific-Basin Finance Journal, 14(4), 327-348. https://doi.org/10.1016/j.pacfin.2006.01.002

Benveniste, L. M. and Spindt, P. A. 1989. How do investment bankers determine the offer price and allocation of a new issue? Journal of Financial Economics, 24(2), 343-361. https://doi.org/10.1016/0304-405X(89)90051-2

Boehmer, E. and Fishe, R.P.H. 2000. Do underwriters encourage stock flipping? A new explanation for the underpricing of IPOs. Working Paper, University of Miami. https://doi.org/10.2139/ssrn.228434

Carter, R.B. and Dark, F.H. 1993. Underwriter reputation and initial public offer: the detrimental effects of flippers. The Financial Review, 28(2), 279-301. https://doi.org/10.1111/j.15406288.1993.tb01349.x

Carter, R. and Manaster, S. 1990. Initial Public Offerings and underwriter reputation. The Journal of Finance, 45(4). 1045-1067. https://doi.org/10.1111/j.1540-6261.1990.tb02426.x

Che-Yahya, N, Abdul-Rahim R. and Yong, O. 2014. Influence of institutional investors' participation in the flipping activity of Malaysian IPOs. Economics Systems, 38(4), 470486. https://doi.org/10.1016/j.ecosys.2014.03.002

Chong, F. N. 2009. Disposition effect and flippers in Bursa Malaysia. Journal of Behavioral Finance, 10(3), 152-157. https://doi.org/10.1080/15427560903167712 
Chong, F. N., Ali, R. and Ahmad, Z. 2009. Does the noise signal effect flipping activities? International Journal of Banking and Finance, 6(2), 111-127.

Chong, F. N., Ali, R. and Ahmad, Z. 2011. Representative heuristics and the aftermarket dynamics of the new listings in Malaysia. Labuan Bulletin of International Business and Finance, $9(1), 1-11$.

Correra, A.J. 1992. Block that sale: the war on IPO flippers hurts the little guy. Barron's National Business and Financial Weekly, 72, 43 (June 1).

Dawson, S. M. 1987. Secondary market performance of Initial Public Offers in Hong Kong, Singapore, and Malaysia, 1974-1984. Journal of Business, Finance and Accounting 4(1), 65-76. https://doi.org/10.1111/j.1468-5957.1987.tb00529.x

Ellis, K., Michaely, R. and O'Hara, M. 2000. When the underwriter is the market maker: an examination of trading in the IPO aftermarket? The Journal of Finance, 55(3), 1039-1074. https://doi.org/10.1111/0022-1082.00240

Fishe, R.P.H. 2002. How stock flippers affect IPO pricing and stabilization? Journal of Financial and Quantitative Analysis, 37(2), 319-340. https://doi.org/10.2307/3595008

Gounopoulos, D., 2006. Activity in a fixed offer price mechanism allocated IPOs. Unpublished Manuscript. University of Surrey, the United Kingdom. 1-24. https://doi.org/10.1016/B978-075067975-6.50014-1

Guo, H.F. and Brooks, R. 2009. Duration of IPOs between offering and listing: Cox proportional hazard models-Evidence for Chinese A-share IPOs. International Review of Financial Analysis, 18(5), 239-249. https://doi.org/10.1016/j.irfa.2009.09.001

Hanley, K.W., Kumar, A.A. and Seguin, P.L. 1993. Price stabilization in the market for new issues. Journal of Financial Economics, 34(2), 177-197. https://doi.org/10.1016/0304405X(93)90017-6

Hanley, K.W., Lee, C.M.C. and Seguin, P.L. 1996. The marketing of closed-end fund IPOs: evidence from transactions data. Journal of Financial Intermediation, 5(2), 127-159. https://doi.org/10.1006/jfin.1996.0008

Islam, M. S. and Munira, S. 2004. IPO flipping and its determinants in Bangladesh. Dhaka University Journal of Business Studies, 25(1), 1-23.

Kahneman, D. and Tversky, A. 1979. Prospect Theory: An Analysis of Decision Making Under Risk, Econometrica, 47(2), 263-289. https://doi.org/10.2307/1914185

Kahneman, D. and Tversky, A. 1982. Intuitive Predictions: Biases and Corrective Procedures. Reprinted in Kahneman, Slovic and Tversky, Judgement Under Uncertainty: Heuristics and Biases. Cambridge University Press, Cambridge, England. https://doi.org/10.1017/CBO9780511809477

Kaustia, M. 2004. Market-wide impact of the disposition effect: Evidence from IPO trading volume. Journal of Financial Markets, 7(2), 207-235. https://doi.org/10.1016/j.finmar.2003.11.002 
Leow \& Lau | The Interaction Effect of Heuristic Representation on Initial Public Offering Anomaly

Krigman, L., Shaw, W. H. and Womack, K. L. 1999. The persistence of IPO mispricing and the predictive power of flipping. Journal of Finance, 55(3), 1015-1044. https://doi.org/10.1111/0022-1082.00135

Miller, R. E. and Reilly, F. K. 1987. An examination of mispricing, returns, and uncertainty for initial public offerings. Financial Management, 16(2), 33-38. https://doi.org/10.2307/3666001

Leow, H.W. and Lau, W.Y. 2018a. The impact of Global Financial Crisis on IPO underpricing in the Malaysian Stock Market. Review of Pacific Basin Financial Markets and Policies, 21(4), 1850023-1 - 1050023-17. https://doi.org/10.1142/S0219091518500236

Leow, H.W. and Lau, W.Y. 2018b. The high-low intraday performance of Initial Public Offerings during the Global Financial Crisis: Evidence from Malaysian stock market. Indonesian Capital Market Review, 10(1), 1-12.

Ritter, J. R. 1984. The "Hot Issue" market of 1980. The Journal of Business, 57(2), 215-240. https://doi.org/10.1086/296260

Sapian, R. Z. Z., Abdul-Rahim, R. and Yong, O. 2012. Underpricing, flipping activity and aftermarket liquidity of IPOs. Jurnal Pengurusan, 34(1), 29-43.

Schultz, P. H. and Zaman, M. A., 1994. Aftermarket support and underpricing of initial public offerings. Journal of Financial Economics, 35(2), 199-219. https://doi.org/10.1016/0304405X(94)90004-3

Shiller, R.J. 2003. From efficient markets theory to behavioural finance. Journal of Economic Perspectives, 17(1), 83-104. https://doi.org/10.1257/089533003321164967

Tversky, A. and Kahneman, D. 1983. Extensional versus intuitive reasoning: The conjunction fallacy in probability judgment. Psychological Review, 90(4), 293-315. https://doi.org/10.1037/0033-295X.90.4.293

Tversky, A. and Kahneman, D. 1974. Judgement under uncertainty: Heuristics and biases, Science, 185(4157), 1124-1131. https://doi.org/10.1126/science.185.4157.1124

Wasserman, N. 2003. Founder CEO succession and the paradox of entrepreneurial success. Organization Science, 14(2), 149-172. https://doi.org/10.1287/orsc.14.2.149.14995

Wong, K. 2005. The aftermarket role of IPO underwriting syndicates in Australia, Working Paper, University of New South Wales.

Yong, O. 1996. Size of the firm, over-subscription ratio, and performance of IPOs. Malaysian Management Review, 31(2), 28-39. 